The Digital Object Identifier - DOI: 10.37952/ROI-jbc-01/20-64-12-104

Submitted on December 20, 2020.

\title{
Study of modern paint and varnish coatings of cars produced by "UAZ" and "Volkswagen"
}

(C) Sergey E. Lebedenko, ${ }^{1}{ }^{+}$Aleksey G. Isaev, ${ }^{2}$ Irina E. Mozoreva, ${ }^{3}$ and Sergey A. Beznosyuk ${ }^{3}$

${ }^{1}$ Forensic Center of the Main Directorate of the Ministry of Internal Affairs of Russia for the Altai Territory. Lenin Ave., 74. Barnaul, 656015. Altai Territory. Russia.

Phone: +7 (3852) 39-29-54.E-mail: lebedenko@list.ru

${ }^{2}$ Forensic Center of the Directorate of the Ministry of Internal Affairs of Russia for the Ulyanovsk Region.

Karl Marx St., 31. Ulyanovsk, 432001. UlyanovskRegion.Russia.E-mail: aisaev5@mvd.ru

${ }^{3}$ Department of Physical and Inorganic Chemistry. Institute of Chemistry of Chemical and Pharmaceutical Technologies. Altai State University. Krasnoarmeisky Ave., 90. Barnaul. 49. Altai Territory. Russia. E-mail: bsa1953@mail.ru

*Supervising author; ${ }^{+}$Corresponding author

Keywords: paints and varnish coatings, varnish, enamel, primer, infrared spectroscopy, scanning electron microscopy.

\section{Abstract}

The article presents the results of a study of samples of factory paint and varnish coatings of cars of the "UAZ" and "Volkswagen" model series in accordance with the methods of studying paint and varnish coatings of vehicles in force in the system of forensic departments of the Ministry of Internal Affairs of Russia. When carrying out the study, a set of recommended methods for studying paint and varnish coatings was used optical microscopy, infrared spectroscopy, electron scanning microscopy with X-ray spectral microanalysis.

In the course of the work, the morphological features of the investigated each layer of the studied paint and varnish coatings were determined, and the infrared spectra of these layers were also recorded and interpreted. Based on the analysis of infrared spectra, the qualitative molecular composition of the main components of soils, enamels and varnishes of paint and varnish coatings was determined. Electronic images of cross-sections of paint-and-lacquer coatings of UAZ and Volkswagen vehicles were obtained, as well as Xray spectra of each layer. The data obtained made it possible to generalize and compare the characteristic features of paint and varnish coatings of each manufacturer. So, for paint and varnish coatings manufactured by Volkswagen, the following characteristics have been determined: the first primers of the samples are made on the basis of a polyester binder containing titanium dioxide in the mineral part, the second primers (fillers) are made on the basis of an acryl-urethane or polyacrylate binder with various modifiers, containing barium sulfate, titanium dioxide and other fillers, the lacquer layers are made on the basis of an acrylic-urethane binder modified with styrene and melamine. The paint and varnish coatings produced by "UAZ" were characterized by the following features: the first primers were made on the basis of an epoxy-ester binder containing various fillers. In the manufacture of the second primers (fillers), an alkyd binder modified with melamine can be used. The available lacquer layers are made on the basis of a polyacrylate binder modified with styrene and melamine.

The identified groups of features make it possible to differentiate the paint and varnish coatings of cars of the UAZ and Volkswagen model lines within the framework of the examination of materials, substances and products.

\section{References}

[1] I.M. Fitsev, V.K. Blokhin, G.K. Budnikov, N.A. Fitseva. Chemical and analytical diagnostics in the forensic examination of materials, substances and products. Industrial laboratory. Diagnostics of materials. 2004. Vol.70. No.4. P.3. (russian)

[2] A.V. Agrafenin, et al. Fundamentals of Criminalistic Examination of Materials, Substances, and Objects: Manual. Moscow: FEC of the Russian Ministry of Internal Affairs. 1993. 208p. (russian)

[3] A.V. Belyaev et al. Forensic analysis of the modern car paints and coatings. Methodological guidelines. Moscow: FEC of the Russian Ministry of Internal Affairs. 1998. 32p. (russian)

[4] V.A. Koptyug (ed.) Atlas of spectra for forensic departments of the USSR Ministry of Internal Affairs. Iss.6. Infrared spectra of car paints. Novosibirsk: NIOCh SB AS USSR. 1987. 212p. (russian)

[5] A.H. Kuptsov, G.N. Zhizhin. Fourier-Raman spectra and infrared absorption of polymers. Moscow: FIZMATLIT. 2001. 656p. (russian)

[6] A.I. Vlasov, et al. Electron Microscopy. A Textbook. Moscow: Publishing house of MSTU im. N.E. Bauman. 2011. 168p. (russian) 